\title{
MARCEL DUCHAMP Y EL FIN DE LAS ARTES FIGURATIVAS \\ Edgar Vite*
}

Objects of every sort are material for the new art: paint, chairs, food, electric and neon lights, smoke, water, old socks, a dog, movies, a thousand other things which will be discovered by the present generation of artists. Not only will these bold creators show us, as if for the first time, the world we have always had about us but ignored but they will disclose entirely unheard of happenings and events found in garbage cans, police files, hotel lobbies, seen in store windows and on the streets, and sensed in dreams and horrible accidents.

Allan Kaprow, The Legacy of Jackson Pollock

$\mathrm{E}_{1}$ arte ha sido una manifestación

que ha acompañado a la humanidad desde sus inicios, revelando tanto la grandeza como la decadencia de los diversos pueblos y culturas. En este sentido podemos comprender las obras de arte como un reflejo del hombre, de sus ideas, de sus pasiones, de sus miedos, de sus deseos y anhelos más profundos. Con el paso del tiempo se han presentado diversas concepciones sobre el arte, dando lugar a un dinamismo constante, en el cual las corrientes emergentes se oponen a las anteriores y luchan incansablemente por tener un lugar en la historia. Uno de los momentos más radicales de dicha evolución artística se dio en la Modernidad, a partir de las vanguardias, las cuales marcaron una clara ruptura con el arte tradicional y dieron lugar a una serie de elementos jamás imaginados.

\footnotetext{
* Maestro en Filosofía por la UNAM.
} 
Me propongo realizar un análisis detenido sobre las condiciones que dieron lugar al abandono de la práctica representacional y a la necesidad de realizar un replanteamiento teórico sobre el arte; un estudio sobre la forma en que evolucionó la pintura y se alejó de la concepción artística tradicional. Al mismo tiempo presento mi propia crítica a la propuesta del filósofo norteamericano Arthur C. Danto en lo que se refiere a su interpretación de que el Pop Art constituyó el caso paradigmático de la mencionada revolución artística.

En contraste con el planteamiento del filósofo norteamericano pienso que el origen de este cambio se dio con la aparición del Dadaísmo, por medio de uno de sus representantes más polémicos, el conocido artista francés Marcel Duchamp. A partir de dicha consideración exploro las características de sus ready-mades, el modo en que alteraron la historia del arte y dieron origen a una serie de principios que pusieron en duda los criterios regentes de la esfera artística. De este modo se dieron las condiciones necesarias para cuestionar la forma de comprender el arte y realizar una reflexión filosófica en torno a su devenir.

\section{Narración e historia del arte}

Antes de entrar de lleno en las características de los ready-mades y al giro que produjeron las obras del artista francés es necesario detenernos a examinar la forma en que el arte se creó y comprendió previamente. En este apartado analizo el concepto de narratividad en el planteamiento de Arthur C. Danto y su interpretación sobre el lugar de la teoría mimética en el desenvolvimiento del arte. Esto nos muestra de fondo que para el autor norteamericano no puede establecerse una adecuada filosofía del arte si no se toma en cuenta su desarrollo histórico.

Para Danto una de las narrativas más comunes, desde la aparición del arte, fue la imitación. Esta forma de entender el arte estuvo conectada estrechamente con un realismo estético y por tanto la finalidad 
artística se fundó como un intento por igualar la belleza natural. En esta medida toda creación artística se constituyó como una mera reproducción de lo real, de modo que una obra de arte era considerada más perfecta entre más se asemejaba a su modelo original. ${ }^{1}$ Sobre este punto es necesario aclarar que el filósofo norteamericano se centra en la forma en que se han desarrollado las artes figurativas y que por tanto su teoría se aplica primordialmente a la pintura:

Por un largo período histórico, fue presupuesto que para ser una obra de arte, especialmente una obra de arte visual, la obra tenía que ser mimética: imitar una realidad externa, actual o posible [...] 'Imitación' era la respuesta filosófica estándar a la pregunta qué es el arte, desde Aristóteles hasta avanzado el siglo XIX, e incluso en el XX. En consecuencia la mímesis, a mi criterio, es un estilo. En el período en el cual la mímesis definía lo que era una obra de arte, no había otro estilo en este sentido de la palabra. ${ }^{2}$

Esta narrativa constituye un caso paradigmático de la historia del arte, cuya meta estuvo determinada por el perfeccionamiento en la imagen y la ilusión óptica. De aquí que durante mucho tiempo la apariencia tuvo un lugar privilegiado, pues mientras una obra se asemejaba más

${ }^{1}$ Sobre este aspecto debemos considerar que no siempre ha existido un interés artístico por representar la realidad con fidelidad. Antes de acercarnos a una obra con ojos críticos y descartarla por el hecho de que no se parezca a algo real, debemos tomar en cuenta cuál es la intención del artista. No podemos considerar del mismo modo un error de técnica que la aparición de una nueva forma de representar la realidad. De otra manera no tendrían lugar manifestaciones como el arte abstracto. Sobre este aspecto Gombrich, el conocido historiador del arte, nos dice lo siguiente: "La paciencia y la habilidad que conducen a la representación fidedigna del mundo visible son realmente dignas de admiración. Grandes artistas de otras épocas han dedicado muchos esfuerzos a obras en las que el más pequeño pormenor ha sido registrado cuidadosamente. El estudio de una acuarela de una liebre por Durero es uno de los más famosos ejemplares de tan acendrada paciencia. Pero, ¿quién diría que el dibujo de un elefante por Rembrandt es forzosamente menos bueno porque presenta menos detalles?" (Gombrich Esencial. Textos escogidos sobre arte y cultura, 1997, Madrid, Debate, Richard Woodfield, p. 69.)

${ }^{2}$ Arthur C. Danto, Después del fin del arte. El arte contemporáneo y el linde de la historia, 1999, Barcelona, Paidós, trad. Elena Neerman, p. 66. 
a lo real, se le otorgaba un mayor valor artístico. ${ }^{3}$ La representación en el arte estuvo vinculada estrechamente con una evolución técnica, la cual tuvo como meta principal el reconocimiento inmediato del modelo original y la producción del goce visual.

Para Arthur C. Danto el arte actual ya no se plantea la imitación como una meta a seguir, pues le parece que las nuevas manifestaciones no sólo superan esta concepción del arte, sino que transgreden los límites a tal grado que el arte termina confundiéndose con lo real, con cualquier cosa del mundo real. Esto no significa que no sigan existiendo obras y artistas representacionistas, sino más bien que se ha dejado de lado esta concepción del arte y se ha dado lugar a nuevas posibilidades. Me parece que se debe en gran medida a que las manifestaciones posteriores se muestran en contra de cualquier tipo de límite:

Las estructuras narrativas del arte representativo tradicional, y también del arte modernista, se gastaron por lo menos en el sentido de que ya no tienen un rol activo que jugar en la producción de arte contemporáneo. Hoy el arte es producido en un mundo artístico no estructurado por ninguna narrativa maestra, aunque por supuesto, queda en la conciencia artística el conocimiento de las narrativas que no tienen más aplicación. ${ }^{4}$

Lo curioso es que al principio el alejamiento de la representación como finalidad del arte produjo una fuerte crítica y una clara incomprensión por parte del público. Las nuevas manifestaciones fueron consideradas inferiores a las anteriores y se creyó que esos artistas eran incapaces de pintar. Dicho conflicto más que derivarse de ciertos prejuicios culturales se produjo como un claro choque entre dos interpretaciones completamente distintas sobre el arte:

${ }^{3}$ A pesar de esta consideración podemos darnos cuenta que en la antigüedad también existieron algunos planteamientos que presentaron una lucha constante en contra de la apariencia, al tomarla como un reflejo de falsedad y mentira. En esta dirección el autor de la antigüedad que más se opuso a la apariencia fue Platón, quien desterró a los poetas de su República ideal, pues creía que estos corromperían a los ciudadanos con sus ficciones y demás creaciones. De manera que podemos considerar que el autor griego fue uno de los primeros en poner un límite y una clara censura a las obras de arte.

${ }^{4}$ Arthur C. Danto, op. cit., p. 68. 
Fue este modelo de pintura el que hizo que la gente dijera inmediatamente que la pintura modernista no era arte. Realmente no lo era, tal como el término era entendido. Y la respuesta espontánea fue que los pintores modernistas no hacían realmente arte superior -no sabían cómo pintar- o que sabían pero recurrían a una visión de la realidad poco común. ${ }^{5}$

Sobre este aspecto de la narrativa representacional Gombrich considera en su Historia del Arte que resulta demasiado exagerado apelar a la apariencia como única meta del arte. Esto se debe a un prejuicio general, el cual consiste en pensar que un pintor es mejor mientras mayor corrección y perfección técnica muestre su obra. El crítico vienés considera que el arte no puede regirse tan sólo por la fidelidad, pues los modos de representación han ido variando, dando lugar a otras formas de expresión:

Hay dos cosas, pues, que deberemos tener en cuenta siempre que creamos encontrar una falta de corrección en un cuadro. Una, si el artista no tuvo sus motivos para alterar la apariencia de lo que vio. Oiremos hablar mucho acerca de tales motivos, como la historia del arte nos revela. Otra, que nunca deberemos condenar una obra por estar incorrectamente dibujada, a menos que estemos completamente seguros de que el que está equivocado es el pintor y no nosotros. ${ }^{6}$

Dicha escisión surgió a partir del Impresionismo, pues gracias a esta corriente la pintura tal como se conocía cayó en una fuerte crisis e inclusive se llegó a creer que era su fin. y en cierto modo fue verdad. ${ }^{7}$ El Impresionismo no sólo dejó de lado el interés de los artistas en la

${ }^{5}$ Ibid., p. 70.

${ }^{6}$ Gombrich, Gombrich Esencial, op. cit., p. 68.

${ }^{7}$ Sobre este punto hay que insistir en que la noción del fin del arte presenta una relación más estrecha con la pintura que con las otras disciplinas artísticas. Esto se debe en gran medida a la crisis por la que pasó la pintura, no sólo en lo que se refiere al surgimiento de nuevas formas de expresión y a la renuncia a la narrativa representacional, sino también a la aparición de otros medios artísticos como el cine y la fotografía. 
representación, sino que presentó una concepción completamente nueva sobre el arte. Al respecto, el filósofo norteamericano considera que la figura encargada de revolucionar la pintura fue Manet:

Esto, si es verdad, nos ayuda a comprender la abrumadora resistencia a los impresionistas cuando realizaron su primera exposición. Pero me interesa subrayar la identificación de Manet como inicio, evidenciando la extraordinaria intuición histórica de Greenberg. Fue precisamente con Manet que Oswald Spengler asoció el fin de la pintura en la Decadencia de Occidente: "con la generación de Manet, todo había terminado". Comienzo o final quedó claro en todo caso que Manet marcó un cambio profundo. ${ }^{8}$

El pintor francés abandonó el carácter simbólico de la pintura y ya no se preocupó por plasmar la realidad con fidelidad. Édouard Manet no sólo revolucionó la técnica pictórica, sino también la manera en que el espectador se enfrentaba al arte. Esto produjo un claro rechazo al arte tradicional y marcó el surgimiento de una nueva era en la pintura $\mathrm{y}$ en el arte en general. Al respecto encontramos uno de sus primeros cuadros, la Olympia de 1863; en dicha pintura a pesar de retomar un tema mitológico relacionado con la narrativa tradicional, lo presenta de un modo completamente distinto, centrándose propiamente en el carácter pictórico del cuadro:

Manet obliga al observador a mirar sobre su cuadro, en lugar de mirar en él; no le permite perderse en una ilusoria profundidad espacial, sino que le incita a contemplar la superficie del lienzo; no sólo quiere mostrar a una muchacha desnuda, sino también la pintura que ha aplicado para representarla. Su realismo corresponde en primera instancia a la realidad del cuadro, y para Manet ésta abarca también el proceso de creación de la obra: este proceso tiene que hacerse perceptible, transparente [...] La espontaneidad, el ritmo y la precisión de la pincelada se convierten en su objetivo principal. Al proceso de la pintura se le atribuye la misma importancia que a su tema. ${ }^{9}$

${ }^{8}$ Arthur C. Danto, op. cit., p. 91.

${ }^{9}$ Sandro Bocola, El arte de la Modernidad: estructura y dinámica de su evolución de Goya a Beuys, 1999, Barcelona, Serbal, trad. Rosa Sala, p. 117-8. 
El Impresionismo muestra de fondo una actitud más empírica con respecto a las corrientes anteriores, de modo que para estos artistas lo importante ya no consiste en lo representado sino en la forma en que es percibido por nosotros. ${ }^{10}$ Este movimiento ya no se centra en la realidad sino en la forma en que somos afectados por ella, de aquí su profundo estudio sobre la refracción de la luz, el color y la forma:

La realidad visible, que en Manet ya ha perdido su significado simbólico, en los cuadros de sus sucesores también pierde su carácter corpóreo y se reduce a la impresión que deja en la retina. Se ve privada de su calidad material y, en este sentido radical, se convierte en mera apariencia, en 'impresión'. Monet y sus amigos ya no muestran su motivo tal y como es, sino tal y como lo ven. Lo que se representa ya no es lo que se percibe, sino el proceso mismo de percepción. ${ }^{11}$

A partir de dicha corriente la pintura dio un giro de 360 grados, pues dejó de preocuparse por los temas de la composición para centrarse en la reflexión sobre sí misma. Esto se debe a que el Impresionismo ya no pone el énfasis en lo representado, sino en los medios de representación. Con respecto a este punto el filósofo norteamericano retoma la teoría de Greenberg, en la cual el crítico considera que a partir de este cambio comenzó el Modernismo y el arte terminó por transformarse en su propio objeto:

Ésta es crítica interna, y significa en efecto, en el caso del arte, que el arte bajo el espíritu modernista, en todo punto, es autocuestionador: lo que significa que el arte es su propio sujeto y, en el caso de la pintura,

${ }^{10}$ Sobre este tipo de reflexión encontramos que los impresionistas europeos comenzaron a adquirir conciencia sobre su manera de pintar, por lo que dejaron de centrar su atención en lo representado, sino en los medios para hacerlo: "A la realidad visible, a lo representable, se le sustrae la calidad de lo concreto y real para transmitírsela, en una exclusividad desconocida hasta entonces, a la representación propiamente dicha, al cuadro pintado. El peso del mensaje artístico se ha desplazado del contenido a lo pictórico, del campo de acción de lo corpóreo al de lo dinámico. Los medios formales son liberados de su anterior función meramente servil y adquieren protagonismo en cuanto portadores de sentido." (Sandro Bocola, ibid., p. 131.)

${ }^{11}$ Ibid., p. 127. 
lo que esencialmente importa a Greenberg, el sujeto de la pintura fue la pintura. El modernismo fue un tipo de indagación colectiva desde la pintura hacia la pintura en el esfuerzo de exhibir qué es la pintura. ${ }^{12}$

La pintura dejó de ser un medio para representar una cosa determinada y se convirtió en un fin en sí misma. Desde la perspectiva de Danto dicha característica no es exclusiva del Modernismo, sino que es compartida por el arte más reciente, el cual también reflexiona sobre los medios y no sólo sobre los temas de la composición. Esto no significa que el arte actual tome como temática central la técnica, sino que las nuevas generaciones de artistas se han vuelto más conscientes sobre su forma de representar:

Desde mi punto de vista, estas validaciones sucedieron cuando la pintura en sí misma llegó a ser un fin más que un medio, y cuando la pincelada indicó que la pintura debía ser mirada antes que mirar a través de ella, en el sentido de que 'a través de' implica transparencia [...] Ver la pintura como pintar significa verla desde el punto de vista del artista, con esta diferencia: los impresionistas aplicaban pinceladas intentando que se fundieran en la percepción del observador, por lo que el ver cosas desde el punto de vista del artista podría haber significado verlas como determinadas por lo que el artista suponía que podría ser el punto de vista del observador si funcionaba la ilusión. ${ }^{13}$

Arthur C. Danto está interesado en conectar su planteamiento con dicha ruptura histórica, pues considera que esto hizo necesario un replanteamiento filosófico en torno a la esencia del arte y el problema de su definición. Esto se debe, desde su perspectiva, a que antes de dicho cambio resultaba relativamente sencillo identificar y clasificar las obras de arte. Para Danto, dicha característica del Modernismo ejerció una fuerte influencia en el arte actual, en el cual existe una mayor preocupación por los medios de representación y la experimentación.

${ }^{12}$ Arthur C. Danto, op. cit., p. 85.

${ }^{13}$ Ibid., p. 93. 
Plantea que esta reflexión del arte sobre sus propios medios abrió las posibilidades a tal grado que dio lugar a la incorporación de una serie de elementos que nunca antes habían pertenecido a su esfera. Desde su perspectiva este hecho provocó en el arte postmoderno uno de los fenómenos más radicales, que consistió en la confusión entre arte y realidad, por lo que la reflexión comenzada en el Impresionismo se volvió aún más urgente.

Danto identifica dicho cambio con la aparición del Pop Art y en concreto de la Brillo Box de Andy Warhol, la cual desde su perspectiva tiene la particularidad de apropiarse de un objeto de la vida cotidiana y presentarlo como una obra de arte. Esta transposición se convirtió en algo extraordinario, pues el arte dejó de tener un lugar exclusivo y delimitado para partir de cualquier cosa que nos rodea:

Mi gran experiencia, frecuentemente descrita, fue mi encuentro con Brillo Box de Warhol en la galería Stable en abril de 1964, el mismo año de la retrospectiva de Hopper en el Whitney. Fue un momento muy excitante, tan sólo porque toda la estructura del debate que había definido la escena del arte de Nueva York hasta ese momento, había dejado de tener aplicación. Se requería una teoría enteramente nueva y diferente de las teorías del realismo, de la abstracción y del modernismo que habían definido la discusión para Hopper, sus aliados y sus oponentes. ${ }^{14}$

Lo característico de la Brillo Box se debe a que ésta abre la esfera de lo artístico y se produce una imitación del modelo a tal grado que parece imposible distinguir la copia del original. Este tipo de obra se ubica como parte del fenómeno de trasposición, en el cual ya ni siquiera es necesario producir un objeto, sino que basta con trasladarlo de un ámbito a otro.

Sin embargo, a lo largo de este análisis me propongo mostrar que dicho cambio se dio con el Dadaísmo y sobre todo con la aparición de los ready-mades de Marcel Duchamp. El mismo Danto realizó una modificación a su planteamiento original, pues en su último libro, The

${ }^{14}$ Ibid., p. 137. 
Abuse of Beauty, considera que el artista francés fue quien provocó dicha reflexión y que no se gestó a partir de Andy Warhol como había pensado originalmente:

Esto se debe en gran parte a que mis intereses han apuntado al establecimiento de una definición filosófica sobre el arte. El tema de la definición del arte se volvió urgente con la aparición del siglo veinte, cuando las obras de arte comenzaron a confundirse con objetos comunes y corrientes, como ocurrió en el notorio caso de los ready-mades de Marcel Duchamp. ${ }^{15}$

A pesar de este reajuste a su teoría, el filósofo norteamericano piensa que en el fondo ambos movimientos responden a un interés común y que presentan una serie de características similares. Sobre este punto es necesario demostrar que dicha interpretación no es correcta, pues ambas corrientes responden a finalidades y principios muy diferentes, de modo que no puede atribuírseles una igualdad de circunstancias ni un proyecto común. Me parece que el hecho de que Danto tome el Pop Art como el paradigma del arte contemporáneo se debe en gran parte a la intención perseguida por los representantes norteamericanos de dicho movimiento, quienes reclamaron para sí la originalidad de las vanguardias europeas y desearon establecer en su nación las condiciones necesarias para el futuro del arte.

\section{El papel de lo cotidiano en el arte}

El Pop Art retomó el modelo de la producción en serie y la industrialización, lo cual se relaciona con su desarrollo en las grandes ciudades como Londres y Nueva York. Por esta razón uno de sus temas centrales fue el urbanismo burgués y la gran mayoría de sus representantes hizo uso del mecanicismo, no sólo como uno de sus temas recurrentes, sino que establecieron una forma de producción artística masiva. Podemos citar la intención manifiesta de Andy Warhol de convertirse en un

${ }^{15}$ Arthur C. Danto, The Abuse of Beauty, 2003, USA, Carus Publishing Company, p. 6. 
hombre-máquina, por lo que inclusive nombró su estudio como The Factory:

Pienso que todo el mundo debería ser una máquina.

Pienso que a todos deberían gustarles los demás.

¿De eso se trata el Pop Art?

Sí, se trata de tener gusto por las cosas.

¿Tener gusto por las cosas es ser como una máquina?

Sí, porque haces lo mismo todo el tiempo.

Lo haces una y otra vez. ${ }^{16}$

Dos de los slogans predilectos de esta corriente fueron el American Way of Life y el American Dream. De este modo encontramos una clara reivindicación de los valores y las costumbres de su pueblo, que se conjugaron en el trillado mito de la tierra prometida. La influencia del capitalismo, los factores económicos, la oferta y la demanda jugaron un papel esencial en esta corriente. El Pop apela a un estilo de vida, pero sobre todo a una calidad de vida por medio de la estabilidad económica. Su propuesta se presentó como una reivindicación de los valores de la clase media. ${ }^{17}$ Así, el paradigma de dicho movimiento fue la burguesía, con la característica de que existía un fuerte deseo de inclusión, pues consideraban que al final todos podían aspirar a dichos valores:

La nueva protesta es a favor de la sociedad, o de la gente en general y se manifiesta en contra de las barreras invisibles que un lienzo o una escultura producen entre el público y el trabajo terminado. Es como si la mayoría de estos artistas trataran de salir de sus obras para darle un buen apretón de manos o un golpe en las costillas a los espectadores. ${ }^{18}$

${ }^{16}$ G. R. Swenson, “What is Pop Art?”, en Pop Art. A Critical History, 1997, California, University of California Press, Ed. Steven Henry Madoff, p. 103.

${ }^{17} \mathrm{La}$ influencia de los valores burgueses en un período artístico no será exclusivo del Pop Art, pues encontramos una situación muy similar en el caso del Impresionismo, en el cual el modelo de la pintura fue la burguesía y el estilo de vida europeo.

${ }^{18}$ Thomas Hess, "Mixed mediums for a soft revolution", en Pop Art. A Critical History, op. cit., p. 10. 
EDGAR VITE

Otro de los elementos que incorporó el Pop Art en la esfera artística fue el conocido Kitsch, como resultado del culto a los estilos y modelos de vida de la sociedad norteamericana. Sobre este punto es necesario tomar en cuenta la crítica que Clement Greenberg realiza a esta corriente, quien considera que el rasgo definitorio del arte Pop fue su búsqueda por la novedad, lo cual en el fondo marcó su propia decadencia. Toda corriente que proclama la innovación como su valor máximo termina por autodestruirse, pues con el paso del tiempo se dará lugar a la experimentación con nuevas posibilidades:

Ninguno de estos artistas puede ser discutido, puesto que su contribución consiste en representar gallinas desplumadas en vez de faisanes muertos o latas de café y repostería en lugar de flores en vasos. Esto no significa que no pueda encontrar clara y directamente la marca académica en sus refrescantes pinturas, después de las turbulencias del Expresionismo Abstracto; sin embargo en el fondo se trata de un fenómeno momentáneo, pues la novedad, que no debe confundirse con la originalidad, no tiene poder de permanencia. ${ }^{19}$

Para Greenberg el Kitsch se constituyó como una forma refinada del mal gusto. ${ }^{20} \mathrm{Si}$ nos detenemos a analizar este fenómeno con mayor detenimiento, podemos darnos cuenta de que dicha corriente estuvo en contra de las obras maestras y de una visión elitista sobre el arte. Lo paradójico de su concepción sobre el arte consiste en que rechazó su carga histórica e intelectual para al final reivindicar un tipo de

${ }^{19}$ Clement Greenberg, "After Abstract Expressionism”, en Pop Art. A Critical History, op. cit., p. 13.

${ }^{20}$ De algún modo lo que Greenberg critica del Kitsch es el hecho de que éste se vuelva una mercancía que responde a las necesidades de una burguesía decadente y carente de verdadera cultura. Y esto se debe en gran parte a que no exige un esfuerzo del público, ni un compromiso intelectual, es un arte demasiado fácil, demasiado complaciente: "El Kitsch es mecánico y opera mediante fórmulas. El Kitsch es experiencia vicaria y sensaciones falseadas. El Kitsch cambia con los estilos pero permanece siempre igual. El Kitsch es epítome de todo lo que hay de espurio en la vida de nuestro tiempo. El Kitsch no exige nada a sus consumidores, salvo dinero; ni siquiera les pide su tiempo."(Clemente Greenberg, Arte y Cultura, 2002, Barcelona, Paidós, trad. Justo G. Beramendi, p. 22.) 
valores propios de la burguesía y el capitalismo. De ahí que sus obras se dirigieran a una élite sustentada en la estabilidad económica, la cual estaba dispuesta a adquirirlas a pesar de los precios desorbitados en que se cotizaban. De esta manera el Pop Art presenta la producción masiva como un modo efectivo de comercialización y consumo artístico, mas no como un medio reflexivo sobre el mismo:

Con ello, al menos, se ha impuesto en determinados ámbitos unas técnicas cuasi industriales de producción, pero éstas no han resultado precisamente 'explosivas', sino que han verificado más bien una completa sumisión del contenido de la obra bajo intereses de rentabilidad, con lo cual las potencias críticas de las obra se reducen en beneficio de una práctica de consumo (incluso en las relaciones humanas más íntimas). ${ }^{21}$

Esta corriente incorpora la cotidianeidad a través de las formas de vida y el carácter comercial del arte. Lo característico de dicha incorporación consiste en que no se realiza una adopción crítica sobre lo cotidiano, sino que resulta suficiente con reproducirlo tal cual. De aquí que haya sido calificada como un arte fácil, complaciente, cínico, banal, vulgar, popular, comprable, mecánico, industrializado, barato, reproducible, jovial, sexy, glamoroso, caprichoso, en pocas palabras, un gran negocio. ${ }^{22}$

En este mismo sentido la aparición de los ready-mades podría interpretarse como un intento de Marcel Duchamp por retomar la estructura y configuración de los medios masivos de producción, así como una incorporación de los diversos elementos que rodean nuestra vida diaria. Sin embargo, me parece que es una característica secundaria de sus trabajos y en esta medida se sitúa muy por encima del arte $P o p$. El artista francés más que realizar una reivindicación de

${ }^{21}$ Peter Bürger, Teoría de la Vanguardia, 2000, Barcelona, Península, trad. Jorge García, p. 75.

${ }^{22}$ Richard Hamilton, "Letter to Peter and Alison Smithson", en Pop Art. A Critical History, op. cit., p. 5-6. 
la cotidianeidad en el arte, trata de mostrar algo que nunca antes había sido asociado con su esfera.

Para Duchamp no se trataba simplemente de retomar los modelos de vida y las costumbres con las cuales el espectador podía identificarse, sino más bien de incorporar una serie de elementos que no correspondían con las obras de arte en esa época. No pretendía una identificación y reconocimiento del público en su obra, sino la producción de un efecto desconcertante.

Esto se debe en gran parte al proyecto del Dadaísmo, movimiento muy polémico desde su aparición, sobre todo por marcar una lucha abierta en contra del arte al procurar destruir cualquier noción estable sobre el mismo. ${ }^{23}$ La serie de situaciones absurdas a las que sometían a los espectadores mezclaban el asombro, la incomprensión y la ironía. Su actitud irreverente, provocativa y en muchas ocasiones claramente prosaica, fue la válvula de escape que abrió el arte hacia una dimensión que nunca antes había sido explorada. El Dadaísmo se caracterizó por su renuncia al progreso artístico, por mezclar lo irracional, lo azaroso, lo espontáneo y lo absurdo para atacar cualquier convención existente en torno al arte:

En el fondo su ataque sarcástico y despectivo a la sociedad burguesa, sus ideales y su lucha estaban dirigidos contra toda estructura de valores o contra cualquier orden imperante: 'Dadá no significa nada' era el

${ }^{23}$ Como mostraré más adelante, el giro radical que encontramos en la obra de Marcel Duchamp y el Dadaísmo consiste en su rechazo a la forma de entender el arte propia de la sociedad burguesa de su época. Esto significa que el ataque principal de este movimiento se dirige a la estabilidad económica y cultural con que se relacionaba el arte. Sobre este punto, Peter Bürger plantea que esta corriente se caracteriza por su rechazo a la institución del arte, así como su crítica a la idea de que las obras son independientes de la vida práctica y por tanto carecen de un compromiso social: "El dadaísmo, el más radical de los movimientos de la vanguardia europea, ya no critica las tendencias artísticas precedentes, sino la institución arte tal y como se ha formado en la sociedad burguesa. Con el concepto de institución arte me refiero aquí tanto al aparato de producción y distribución al que está sometida la obra de arte, y contra el status del arte en la sociedad burguesa descrito por el concepto de autonomía", cfr. Peter Bürger, op. cit., p.62; (V. también Malcolm Cowley, "La religión del arte", en Estudios, n $^{\circ} 79$, nueva época, invierno 2006, p. 7-36. N. del E.) 
mensaje (o antimensaje) del movimiento, expresado mediante infinitas variaciones. Este punto de vista, que resulta ventajoso en la medida en que es únicamente negativo, ejercía cierta atracción sobre los círculos 'progresistas', es decir, antiburgueses. ${ }^{24}$

Sobre este punto es necesario considerar que la intención de desorientación en el arte no es una característica exclusiva de la obra de Marcel Duchamp, sino que corresponde a un efecto procurado por las vanguardias en general, efecto que desde la perspectiva de Peter Bürger, se acentuó con el proyecto de los formalistas rusos. Lo relevante de este elemento en la obra del artista francés se debe a que se constituye como una crítica a la recepción unívoca del arte y, sobre todo, se cuestionan los principios que nos permitían comprenderlo:

Cuando los formalistas rusos hacen del 'extrañamiento' el procedimiento artístico, el conocimiento de la generalidad de esta categoría permite que en los movimientos históricos de vanguardia el shock de los receptores se convierta en el principio supremo de la intención artística. El extrañamiento efectivo se convierte, de esta manera, en el procedimiento artístico dominante y puede al mismo tiempo ser distinguido como categoría general. ${ }^{25}$

El Dadaísmo usaba el arte como un medio para criticar la cultura y la sociedad de su época. En contraste con el Pop Art, esta corriente atacó directamente al capitalismo y la burguesía como parte de su crítica a la estabilidad económica, social y por supuesto artística. De este modo nos damos cuenta del fuerte activismo que existió en las vanguardias, las cuales se mostraron en contra de la noción del arte por el arte y buscaron reincorporarlo a la vida práctica. Esto se debe a que para dichos movimientos el arte tuvo una marcada función social y por tanto no puede tomarse como algo independiente. El arte para las

${ }^{24}$ Sandro Bocola, op. cit., p. 328.

${ }^{25}$ Peter Bürger, op. cit., p. 56. 
vanguardias no puede comprenderse como una manifestación neutral, cuya única finalidad reside en sí mismo:

La teoría de l'art pour l'art no es sencillamente la reacción contra un nuevo medio de reproducción (por mucho que éste haya llevado al ámbito de las artes plásticas la tendencia hacia la total independización del arte), sino la respuesta al hecho de que en la sociedad burguesa desarrollada, la obra de arte pierde progresivamente su función social. (Hemos caracterizado este desarrollo como pérdida del contenido político de las obras concretas.) No se trata de negar la importancia de la transformación de las técnicas de reproducción para el desarrollo del arte, pero no se puede deducir éste de aquélla. ${ }^{26}$

Los dadaístas más que producir arte se encargaron de destruirlo y de esta manera negarlo. Dicha actitud implicó una forma de antiarte, la cual se acentuó con la aparición de Marcel Duchamp. Como ejemplo de dicha actitud irreverente encontramos una de sus primeras obras, con la cual cuestionó los cánones estéticos propios del arte tradicional. Me refiero en concreto a su famosa L.H.O.O.Q., una reproducción de la Mona Lisa a la cual le pintó barba y bigote. ${ }^{27}$

La incorporación de elementos de la vida cotidiana en ambas corrientes responde a intenciones muy diferentes. Inclusive me parece necesario apuntar que la propuesta de Marcel Duchamp fue más audaz que la de su grupo. En esta medida la figura del artista francés se proyectó por encima de la burla al público y la crítica incisiva al arte, correspondientes al Dadaísmo, para dar lugar a una profunda reflexión sobre su esencia.

${ }^{26}$ Ibid., p. 79.

${ }^{27}$ De este modo vemos cómo el artista francés critica los cánones estéticos y en especial se manifiesta en contra de la idea de que el arte es intocable, sobre todo en lo que respecta a las obras maestras. Por tanto Duchamp elimina la idea de que el arte pertenezca a un ámbito restringido y estable. La interdisciplinariedad y la mezcla de diversas técnicas va a formar una parte esencial en dicha crítica, por lo cual en este período el collage adquirió mucha fuerza. (Cfr. Sandro Bocola, op. cit., p. 329.) 


\section{Alteración y manipulación del contexto}

El Pop Art se inspiró en una serie de elementos propios de la publicidad y los medios masivos de comunicación; retomó una diversidad de características del diseño gráfico por las cuales un producto resulta atractivo y se vuelve un medio eficaz para atrapar al consumidor. Al respecto tenemos el caso de Lichtenstein, quien reutilizó el modelo y la técnica que solía emplearse en las tiras cómicas, incluyendo el uso de los Ben Day Dots y las burbujas de diálogo. Lichtenstein más que inventar una nueva forma de representación hizo obras de arte a partir del cómic:

¿Por qué -la gente comenzó a preguntarse-Lichtenstein escoge como tema algo que resulta tan banal, trivial y vulgarmente comercial?

Sólo porque es de esa forma, responde Lichtenstein. Es desafiante, dice, tratar de hacer arte a partir de lo que no es arte. Son ilustraciones baratas tan crudas, tan sencillas, tan familiares, las cuales aparentemente se niegan a transformarse en arte. ${ }^{28}$

Como he mencionado, dicha corriente se vio fuertemente seducida por la novedad, lo cual se debió en gran medida a la fascinación de estos artistas por la moda. El Pop Art tomó la apariencia como su tema central, por lo que sus paradigmas fueron la televisión, la publicidad, la farándula y el glamour. Dicho interés en la apariencia responde en gran medida a que la sociedad de su época se preocupaba por la vida lujosa y los escándalos de personalidades como Elvis Presley, Marilyn Monroe y Jackie Kennedy, entre otras. En esta medida podemos clasificarlo como un arte exhibicionista que reclama ser contemplado y en última instancia admirado. De aquí que los representantes del Pop recurran constantemente a la imagen en sus dos formas más usuales, me refiero en concreto al ícono y al estereotipo, con la intención de presentarlos como obras de arte.

${ }^{28}$ Dorothy Seberling, "Is he the worst artist in the U.S.?", en Pop Art. A Critical History, op. cit., p. 195-6. 
Decir que un objeto es asimbólico es negar que su apariencia puede propagar ciertas vibraciones de significado: el objetivo del Pop Art (esto produce una verdadera revolución en el lenguaje) no es metafórico, ni metonímico, sino que se presenta en sí mismo separado de su fuente y circunstancias; el artista pop no se encuentra detrás de su trabajo y él mismo carece de profundidad; él no es más que la superficie de sus pinturas: no hay significado, ni intención, en ninguna parte. La cultura de masas no es más un elemento del mundo natural; lo que sí se presenta como un hecho es el estereotipo: lo que todo el mundo ve y consume. El Pop Art encuentra la unidad de sus representaciones, basándose en la conjunción radical de estas dos formas llevadas al extremo: el estereotipo y la imagen. ${ }^{29}$

Desde la perspectiva de Danto, el Pop Art se caracterizó por cambiar de ámbito una serie de factores propios de la esfera comercial y trasladarlos a la esfera artística. El autor norteamericano piensa que esta corriente hizo uso de la recontextualización para poner el énfasis en el objeto, pero a su vez mantener la referencia acostumbrada. Por esta razón el Pop acentúa en grado extremo la experiencia que produce un cierto elemento de la vida cotidiana:

El nuevo arte dibuja a partir de imágenes y objetos de la vida cotidiana. Éstos son extraídos de su contexto ordinario, tipificados e intensificados. Nosotros nos quedamos con una conciencia clara de la imagen y del objeto, así como del contexto del cual han sido separados, el cual forma parte de nuestro ambiente. ${ }^{30}$

Los representantes del Pop Art presentaban una intensa proyección de las características que un objeto muestra en la vida diaria. Dicha alteración del contexto implica una cierta ambigüedad e indeterminación, con lo que el espectador se ve obligado a completar la obra, a brindarle aquello que le falta, por lo que el arte se vuelve un juego constante entre el creador y su público:

\footnotetext{
${ }^{29}$ Roland Barthes, "That old thing art ...”, en Pop Art. A Critical History, op. cit., p. 372.

${ }^{30}$ Henry Geldzahler, "A Symposium on Pop Art", en Pop Art. A Critical History, op. cit., p. 67.
} 
Desde que el objeto escogido, en un cierto sentido es banal, los nuevos artistas han sido acusados de sentir nostalgia por la infancia, un efecto que está relacionado por la sencillez con que nos presentan sus objetos. Estos artistas apelan intencionalmente a nuestro gusto por lo simple, llamando la atención en el espíritu y no en los hechos del apetito infantil, por una razón muy similar a la de una generación temprana de pintores que regresaron al arte infantil, como un modo de rescatar la inmediatez y la intensidad de la percepción. La forma en que estos artistas han hecho que los objetos funcionen ambiguamente e indeterminablemente nos remite a un momento de la historia humana, en el cual los espíritus se escondían en todo rincón, dentro de los objetos, haciéndolos moverse o romperse, inclusive matar o curar. ${ }^{31}$

A través de este fenómeno, el Pop Art nos hace pasar de la función utilitaria del objeto a una dimensión estética del mismo. Lo anterior significa para Danto que dicha corriente pretende llamarnos la atención sobre un aspecto del objeto, el cual no tiene nada que ver con su uso práctico y por tanto da lugar a una experiencia nueva sobre el mismo. ${ }^{32}$ Esto se debe, en su opinión, a que el arte Pop nos pide que dejemos de tomar en cuenta la finalidad práctica del objeto para centrarnos en su cualidad, por lo que en dicha corriente todavía podemos hablar de una pretensión estética:

Todos estos objetos inofensivos son extraídos y manipulados con la intención de ser desviados de su función cotidiana hacia una finalidad estética. Aquí se conforma la disfuncionalidad. Para tornar estas armas

${ }^{31}$ Alan Solomon, "The New Art", en Pop Art. A Critical History, op. cit., p. 96.

${ }^{32}$ De manera que esta corriente presenta una especie de revelación, en la cual el uso ordinario de un objeto determinado es sustituido por una emoción estética producida por dicho objeto: "In Mr. Jani's definition of the 'new realist' art, the touchstone is the 'daily object' so manipulated that esthetic emotion is allowed to replace functional usage [...] This is one of the most interesting developments in the galleries, for it marks the entrance of artists into social criticism with ephimeral works that can be thrown away when circumstance has changed enough to remove their relevance. America has been a pioneer in throw away cups and saucers, milk containers, and tablecloths. Now it is a pioneer in throw away art." (Cfr. Brian O'Doherty, “Art: Avant-garde Revolt”, en Pop Art. A Critical History, op. cit., p. 41.) 
entumidas y desafiladas de la industria, los exhibicionistas (aquí la palabra artista requiere de una redefinición) hacen uso de estas trampas estándares de una minoría educada en contra de una mayoría que ellos indulgentemente desprecian: ingenio, sátira, ironía, parodia, todas estas divisiones del humor. Los exhibicionistas tienen una gran ventaja: el objetivo es conocido por ellos y por su audiencia. El sentido es tan grande que resulta difícil no encontrarlo. ${ }^{33}$

Sin embargo, yo considero que el fenómeno de la ambigüedad y la recontextualización no se originó en el Pop Art, sino que surgió con el Dadaísmo y la figura de Marcel Duchamp, además de que con él adquirió su sentido más profundo. A lo largo de su carrera, se interesó por la ambigüedad de las palabras y la pluralidad de significados que puede tener un mensaje o un objeto. La posibilidad jugó un papel muy importante en sus obras; sobre este punto encontramos algunos trabajos en los cuales el artista francés generaba una serie de equívocos entre lo que representaba y la forma en que lo nombraba. ${ }^{34}$

Para lograr tal efecto combinaba las palabras con imágenes, de las cuales eliminaba el referente o lo volvía confuso. De este modo, podemos apreciar la preocupación de Duchamp por la diversidad de interpretaciones a las que puede someterse tanto la esfera artística como la realidad. Una obra que nos permite ilustrar la mencionada ambigüedad es una pintura realizada en 1910, Le Buisson. En este cuadro se representan dos desnudos femeninos junto a un arbusto; Duchamp al titular la obra El arbusto no toma en cuenta la totalidad del referente y sugiere que el espectador es un voyeur, puesto que lo que mira no solamente es un arbusto, sino también los desnudos situados a su lado. ${ }^{35}$

${ }^{33}$ Idem.

${ }^{34}$ La ambigüedad no sólo forma parte de sus obras, sino que se extiende a su propia personalidad y en especial de su identidad sexual. Como claro ejemplo de esto tenemos su alter ego femenino, Rose Sélavy, quien aparecerá en un gran número de sus obras. (Cfr. Dalia Judovitz, Unpacking Duchamp. Art in transit, 1998, Berkeley, University of California Press, p. 144.)

${ }^{35}$ Ibid., p. 23. 
El artista francés descubrió que por medio del desplazamiento físico de los objetos se develan una serie de paradojas artísticas que ponen en duda la identidad del arte. Sobre este aspecto de su obra encontramos varios ejemplos ilustrativos, especialmente en el caso de sus ready-mades: "La suspensión visual del porta-botellas y del porta-sombreros muestra su estatus ambiguo como objetos ordinarios. Colgados de un soporte, se vuelven inaccesibles como objetos funcionales. El perchero, por otro lado, resulta redundantemente funcional al estar sujeto al piso." ${ }^{\prime 36}$

Nos damos cuenta de que la ambigüedad no sólo formaba parte de sus experimentos con el lenguaje, sino que conformaba una temática constante en sus obras. Dicha ambigüedad se generaba a partir de una serie de manipulaciones que producían un efecto desconcertante en el espectador, sugerían una nueva lectura sobre el objeto exhibido y, en último término, una reinterpretación sobre el mismo. ${ }^{37}$

Para lograr dicho efecto, Duchamp incorporaba un objeto determinado a un ámbito ajeno, introducía en el museo algo que no pertenecía a él e inclusive alteraba la noción misma de museo ${ }^{38}$ En este último caso la recontextualización se conforma como la incorporación del museo a la vida cotidiana, como el acceso de algo extraño a un ámbito al que estamos acostumbrados. Una obra que muestra este fenómeno es $L a$ caja en una valija, en la cual apreciamos una serie de reproducciones en miniatura de algunas de sus obras que pueden trasladarse a donde se desee, pues el dueño las porta consigo.

${ }^{36}$ Ibid., p. 94.

${ }^{37}$ No podemos olvidar que Duchamp se rebela frente a las convenciones artísticas, pero sobre todo se opone a la noción de que el arte es representacional, y copiar fielmente la realidad ya no será una meta del arte. En cambio, dicha concepción será sustituida por un paso constante entre el sentido y el sinsentido: "More precisely, the ready-mades stage the interplay of sense and nonsense, since they are punning visual and verbal allusions to the meaning of art as a medium of reproduction. In this context, nonsense is no longer opposed to commonsense. Rather, nonsense implies destruction of the referential status of both pictorial and linguistic meaning through its punning associations to different senses. The ready-made thus emerges as a rhetorical intervention, signifying Duchamp's strategic operation on the terms that have come to define the parameters of artistic experience." (Ibid., p. 77.)

${ }^{38}$ Ibid., p. 149. 
Otro modo de alterar la estructura del museo en cuanto recinto del arte es por medio de una instalación transformando su atmósfera usual. Un ejemplo de dicha manipulación lo encontramos en una obra póstuma, Dado (Etant Donnés) de 1966, una puerta con pequeños orificios a través de los cuales se ve la representación de un desnudo femenino. ${ }^{39}$ Con este trabajo Duchamp nos muestra un tipo muy particular de ready-made, el cual incorpora en su obra un espacio determinado. En este caso la intervención consiste en instalar una puerta que no conduce hacia ninguna parte dentro del museo, sino a la obra del artista.

De este modo podemos darnos cuenta que hace uso de la ambigüedad y la recontextualización como un modo constante de experimentación, con la intención de replantear el estatuto del arte y cuestionar cualquier noción estable sobre éste, a diferencia del Pop Art, que hace uso de ambos elementos para reivindicar el lugar común como parte de la esfera artística y ampliar la dimensión estética en donde no existía.

\section{La presentación vs la representación}

Como he mostrado, el Pop Art reivindica una serie de elementos de la cotidianeidad como parte de la obra artística y su forma de hacerlo es reproduciéndolos. Por esta razón me parece que este movimiento sigue muy apegado a una concepción tradicional sobre el arte. Para los artistas de dicha corriente la imitación tuvo un valor innegable, por lo que imitaban incansablemente los diversos objetos que los rodeaban. De aquí que se inspiraran en el modelo capitalista, la cultura de masas y la publicidad, incorporando una serie de rasgos con los que se identificaba la sociedad norteamericana. ${ }^{40}$

${ }^{39}$ Cfr. David Hopkins, After Modern Art: 1945-2000, 2000, New York, Oxford University Press, p. 40.

${ }^{40}$ Por esta razón en el arte Pop se muestra una búsqueda por continuar con el progreso técnico del arte representacional y su innovación radica en el tipo de elementos de la vida cotidiana que selecciona. Por tanto, el tipo de cambio que muestra esta corriente con respecto 
Los artistas Pop estaban obsesionados con la repetición en una gran variedad de niveles. En primer lugar, dicha repetición hace referencia al hecho de retomar un elemento de la vida cotidiana y representarlo tal cual. En este caso no existe una diferencia radical entre esta corriente y las anteriores, pues copiar la realidad ha sido una finalidad constante en el arte. Por otro lado, la repetición hace alusión al aumento de la proporción; el tamaño excesivo fue uno de los caprichos de este movimiento, teniendo como consecuencia la desmesura y el desequilibrio. El arte Pop pretendía revelar la grandeza por medio de la superación de los límites materiales, por lo que reproducían helados, pasteles, hamburguesas y latas de coca cola enormes:

La repetición es otra de las consecuencias inevitables de este ambiente, dicha repetición juega un papel en el estilo de cada artista. Las acumulaciones, objetos pintados o configurados en grandes dimensiones, son un leitmotiv propio de este Nuevo Realismo. La multiplicación de objetos producidos masivamente y transformados en acumulaciones producen una intensificación en la experiencia visual del espectador. ${ }^{41}$

Otro sentido de repetición es el correspondiente a la rutina, a las cosas que hacemos una y otra vez, a la serie de hábitos que rodean nuestra vida diaria. Aquí encontramos los experimentos visuales de las películas de Andy Warhol, en las cuales se muestra la repetición de una acción al grado que se anula el movimiento, por lo menos aparentemente:

al arte anterior es una diferencia de orden formal. En cambio, las vanguardias rechazan tajantemente esta manera de entender el arte y sobre todo se muestran en contra de una evolución técnica. Por esta razón su interés en el arte se refiere sobre todo a su implicación política y social, de modo que el arte en las vanguardias implica un claro compromiso: "Aquí la pérdida del aura no se deduce del cambio en las técnicas de reproducción, sino de la intención de los productores de arte. La transformación del 'carácter completo del arte' no es aquí el resultado de innovaciones tecnológicas, sino que está mediado por la conducta consciente de una generación de artistas.” (Cfr. Peter Bürger, op. cit., p. 73.)

${ }^{41}$ Janis Sidney, "On the theme of the exhibition", en Pop Art. A Critical History, op. cit., p. 39. 
Las películas de Warhol tienen como tema la pasividad, la magnificación y la repetición. Sleep muestra a un hombre durmiendo durante seis horas, reproduce la acción interminablemente, lo cual evita distinguir la acción presente de dormir [...] Eat presenta a un pintor masticando, masticando, masticando, y la cámara grabando pasivamente la no-acción. El descanso, la sexualidad y la nutrición son demandas repetidas en la vida de una persona, que requieren de una satisfacción continua. ${ }^{42}$

Este tipo de manifestación artística no rompe con el naturalismo implícito en la narrativa representacional, pues busca plasmar la serie de sucesos que nos rodean por más insignificantes que parezcan. Por ello, el Pop Art sigue muy unido al arte tradicional y la vitalidad de sus obras reside en su intención descriptiva. De aquí que en dicho movimiento no exista una revolución radical, como trata de demostrar el filósofo norteamericano. En el fondo me parece que la novedad de este movimiento consiste en la alteración temática de la representación y no en una oposición a la misma.

En cambio, en el caso de Marcel Duchamp nos encontramos con un creador, quien en su propia evolución artística abandonó la pintura y abrió el camino a una nueva forma de experimentación, la cual terminó por separar al arte del curso que había marcado la narrativa representacional. ${ }^{43}$ El controvertido artista francés se inició en la pintura a la edad de quince años y fue experimentando, cambiando de una corriente a otra, siguiendo incansablemente lo que su intuición le dictaba.

Duchamp pasó del arte figurativo al arte abstracto, brincando del Impresionismo al Cubismo. Sobre su influencia cubista, encontramos

${ }^{42}$ William Wilson, "Prince of Boredom. The repetitions and passivities of Andy Warhol", en Pop Art. A Critical History, op. cit., p. 292.

${ }^{43}$ El carácter innovador del modernismo reside precisamente en que rechaza totalmente el carácter tradicional del arte. Lo llamativo de esta ruptura histórica consiste en que va más allá de una simple modificación estilística o temática del arte, pues en el fondo realiza una fuerte crítica al arte tradicional: "Lo que distingue la aplicación de la categoría de lo nuevo en lo moderno de cualquier aplicación precedente, enteramente legítima, es la radicalidad de su ruptura con todo lo que hasta entonces se considera vigente. Ya no se niegan los principios operativos y estilísticos de los artistas, válidos hasta ese momento, sino la tradición del arte en su totalidad.” (Cfr. Peter Bürger, op. cit., p. 120.) 
una de sus obras más importantes, el Desnudo descendiendo una escalera de 1912, en el cual hace uso de la técnica cubista. Lo curioso es que cuando apareció esta obra, los mismos cubistas lo rechazaron por no considerarlo suficientemente apegado a sus principios. Esto se debe en gran medida a que no se conformaba con los modos de pintar establecidos y comenzó a experimentar con técnicas y materiales diversos. En este período de su producción descubrió ciertos elementos que formaron una parte clave en sus manifestaciones posteriores. ${ }^{44}$

Por otro lado, criticó a las corrientes pictóricas que tomaron como eje central la perfección en la representación. Marcel Duchamp denominó este afán de imitación en el arte como una actitud retinal. El error de dicha finalidad consiste en que se centra demasiado en nuestra experiencia visual y desde su perspectiva la pintura y el arte en general no se reducen a la inmediatez de la experiencia, sino que implica la existencia de otros valores y funciones. ${ }^{45}$ A pesar del predominio de dicha narrativa en su época, no se sentía conforme con ella. Al respecto, en una entrevista con Cabanne dijo lo siguiente:

Desde Courbet se ha creído que la pintura está destinada a la retina. Ese fue el error de todos. ¡Lo retinal es escalofriante! Antes que nada la pintura posee otras funciones, puede ser religiosa, filosófica, moral. Si yo tengo la oportunidad de lograr una actitud antiretinal, esto no ha producido un gran cambio desafortunadamente; todo nuestro siglo es completamente retinal, a excepción de los surrealistas, quienes trataron de salir de ahí, y sin embargo no fueron muy lejos. ${ }^{46}$

Dicha característica es compartida por otros autores vanguardistas, quienes se encargaron de analizar algunos problemas que se dan en torno a la forma de comprender e interpretar el arte. Al respecto tene-

${ }^{44}$ En este período Duchamp se situaba como un pintor renombrado internacionalmente y a su vez comenzaba a cuestionar el valor de la pintura. Para el año de 1913 abandonó las formas convencionales de pintar y comenzó a experimentar con la casualidad y con el azar como parte integral de su obra. (Cfr. Dalia Judovitz, op. cit., p. 16.)

${ }^{45}$ Cfr. David Hopkins, op. cit., p. 38.

${ }^{46}$ Dalia Judovitz, op. cit., p. 26. 
mos un ejemplo en el conocido surrealista belga, René Magritte, quien titula su pintura sobre una pipa Esto no es una pipa para mostrar por medio de este gesto que lo representado no puede equipararse con lo real y que dicho prejuicio se debe a una confusión en la interpretación del espectador, pues en sentido estricto no se trata de una pipa sino de la represtación de una pipa. ${ }^{47}$ De esta forma el pintor belga realizó una crítica a la forma tradicional de comprender el arte y a su vez cuestionó la vigencia de la práctica representacional.

En esta medida, las últimas pinturas de Duchamp nos presentan una mezcla entre su influencia del arte abstracto y su incorporación de la ambigüedad. En dicho período produjo una serie de pinturas que dieron lugar a la transición más importante en su carrera. Por sus características, dichas obras han sido denominadas 'pinturas conceptuales', y su nombre se debe justo a que ponen el acento en la idea y no en la representación. Estos trabajos fungen como modelo y antecedente de sus obras posteriores no pictóricas, como El paso de la Virgen a la Prometida:

La pintura El paso de la Virgen a la Novia literaliza la transición que Duchamp efectúo entre la pintura visual y la conceptual. La resonante tensión que sostiene este trabajo entre la abstracción y la figuración se amplifica por el juego del lenguaje que produce el título. Este trabajo muestra la transición entre dos trabajos, la Virgen No. 1 y la Virgen No. 2, la cual es un estudio de la pintura conocida como la Novia. ${ }^{48}$

El artista francés incorporó en sus obras una variedad de medios y materiales nuevos. Dicha experimentación con el medio marca una clara ruptura con el arte anterior y sobre todo con la pintura. ${ }^{49}$ Duchamp

${ }^{47}$ Cfr. David Hopkins, op. cit., p. 165.

${ }^{48}$ Dalia Judovitz, op. cit., p. 44.

${ }^{49}$ Una obra que muestra la transición entre el arte pictórico y el arte objeto es la Cama de Robert Rauschenberg, en la cual se nos presenta una cama colocada verticalmente, lo cual nos remite inmediatamente a los ready-mades, pero además dicha cama está vertida de manchas de pintura, haciendo referencia a la narrativa representacional. (Cfr. David Hopkins, op. cit., p. 44-5.) 
consideraba que la inestabilidad forma parte de la obra, pues la materia se somete al tiempo y por tanto al cambio. Al respecto tenemos su Gran Vidrio, con el cual rompe la noción de cuadro pictórico, pues renuncia al lienzo y al marco, por la traslucidez del vidrio. Esto no sólo implica un distanciamiento de los medios convencionales de la pintura, sino la idea de una renovación constante de la obra, pues dependiendo de su ubicación y de la posición del espectador se producirá un efecto distinto:

Usando vidrio, Duchamp reduce la noción de background pictórico hacia un ready-made, un ready-made que cambia debido a la posición del vidrio. La referencia entre la figura y su background no emerge de la lógica interna de la imagen, sino como un producto de su encuentro casual con el mundo. Este gesto libera el tema de la pintura, la figura, de su relación referencial hacia la representación, y la redefine como un nuevo sitio. ${ }^{50}$

Marcel Duchamp abandonó la pintura y buscó otros medios para manifestarse y para fundar su propia concepción sobre el arte. Se alejó de la tradición e incluyó en sus obras elementos que no habían sido incorporados en la esfera artística. Uno de estos elementos fue la casualidad, como parte del proceso creativo, con lo cual trataba de mostrar que el artista no puede tener todo bajo control, aún en el caso de su propia obra. ${ }^{51}$ Este aspecto fue compartido por las vanguardias en general y al respecto tenemos la action painting de Jackson Pollock, con la cual opone la arbitrariedad personal frente a la necesidad objetiva del realismo pictórico:

${ }^{50}$ Dalia Judovitz, op. cit., p. 60.

${ }^{51}$ La casualidad juega un papel muy importante en lo que se refiere a la configuración del arte contemporáneo pues éste incorpora una serie de elementos que son independientes de la obra, con lo cual se elimina la noción de control y necesidad en el arte. De manera que encontramos casos paralelos en otras obras y artistas, como el caso del controvertido artista John Cage, quien incorporó el azar como parte de la composición musical. (Cfr. David Hopkins, op. cit., p. 41-2.) 
Se trata de mojar la tela con el pincel. La realidad ya no es formada, ni interpretada: se renuncia a la creación intencionada de figuras a favor de un desarrollo de la espontaneidad; el azar abandona en buena medida la figuración. El pintor, liberado de toda pretensión y regla formal, se entrega finalmente a una subjetividad vacía. ${ }^{52}$

Por otro lado, Duchamp incorporó el azar para hacer ver que la obra y el arte mismo no siguen un sólo camino. En este período comenzó a centrar su atención en los objetos y dejó de lado las representaciones; de este modo surgieron los antecedentes de los ready-mades, en los que se encargó de manipular los diversos materiales y utensilios, dándole el mayor peso a la serie de ideas con que trabajaba:

Como Duchamp mismo notó, Tres interrupciones estándares representa un giro radical en su trabajo, pues no sólo marca su abandono de la pintura, sino de las nociones convencionales del arte. Este trabajo es un ensamblaje (un semi-ready-made) que consiste en una caja de croquet que contiene tres dispositivos de medida separados, los cuales se conformaron individualmente por operaciones azarosas. Tres hilos diferentes de un metro de longitud fueron arrojados en lienzos pintados de azul y llenos de pegamento. Las impresiones resultantes, que capturaban la curva de su configuración casual eran sujetadas a unas vitrinas. Estas vitrinas sirvieron de impresión para tres templetes de madera. ${ }^{53}$

La obra nos muestra de fondo una clara ironía en lo que respecta al sistema métrico, pues hace ver que todo principio establecido puede violarse y dar pie a otras posibilidades. En este sentido nos encontramos con el principio de su producción posterior, pues no sólo se trata de una crítica a los límites del arte, sino de las convenciones en general.

Duchamp no pretendía fundar una corriente ni establecer nuevos cánones estéticos. A pesar de que se le ha relacionado estrechamente con los dadaístas, debemos considerarlo como un artista independien-

${ }^{52}$ Peter Bürger, op. cit., p. 128.

${ }^{53}$ Dalia Judovitz, op. cit., p. 47. 
te y muy original. Desde mi perspectiva, su obra debe ser tomada por su característica más importante, que consiste en la ampliación de los límites del arte a tal grado que resulta indispensable cuestionarlo y redefinirlo. Por todo esto es posible comprender su rechazo a la concepción tradicional y al carácter figurativo del arte. ${ }^{54}$

\section{El arte objeto y el ready-made}

Una de las principales intenciones del Pop Art fue demostrar que el mundo del arte no estaba restringido y que sus límites se habían abierto hacia aquello que no formaba parte de él. En esta medida encontramos la propuesta de Andy Warhol para quien las posibilidades del arte se abrieron a tal grado que cualquier cosa podía tomarse como tal..$^{55}$ Para el filósofo norteamericano dicha característica de sus obras ejerció una clara influencia en el desarrollo posterior del arte:

"Todo es arte", dice Warhol. "Vas a un museo y te dicen que los pequeños cuadros colgando de la pared son arte. Pero todo es arte y nada lo es. Esto se debe a que para mí todo es hermoso, si es correcto.” Para Warhol 'correcto' significa que no sea fingido, ser lo que realmente eres, y la diferencia entre correcto e incorrecto es el estilo. "Estilo como lo

${ }^{54}$ Por otro lado, algunos críticos consideran que Duchamp más que ser un artista es un gran estratega del arte, pues les parece más relevante su actitud frente al arte, que sus propias obras. En este sentido Duchamp fue capaz de eliminar la competencia, al realizar algo que nunca antes hubiera sido aceptado en la esfera artística, pues no tenía ningún precedente histórico: "En la medida en que con su objeto demostrativo Duchamp ignora por completo las ambiciones y los ideales del arte anterior a él, consigue apartar a los competidores de su camino sin necesidad de enfrentarse a ellos. En el campo de batalla así definido, él es el único luchador y, por tanto, resulta invencible. Su logro no puede ser repetido, ni superado." Sandro Bocola, op. cit., p. 297.

${ }^{55}$ Sin embargo, como he ido mostrando, la idea de convertir todo en arte, de ampliar las posibilidades para que cualquier cosa se tome como tal, no es originaria del Pop Art, sino que ya se había dado en las vanguardias, sobre todo en el caso del Dadaísmo, el cual superó los límites al tratar de destruir el arte. El modo de lograrlo fue por medio de la presentación de algo que estuviera completamente alejado de esta esfera, con lo que se producía un claro desconcierto y se cuestionaba radicalmente lo que se entendía por arte. 
EDGAR VITE

entiende Kooning o Kline. Emana de la fuerza de su brocha, la energía, el carácter, no sólo la técnica para pintar." ${ }^{56}$

En un principio Danto consideró que el Pop Art descubrió un sentido de apariencia que no hace referencia a la imaginación, ni a la falsedad sino simplemente a la presencia, al modo en que se nos muestran las cosas en el mundo. ${ }^{57}$ Desde su perspectiva, este sentido de presencia fue lo que dio lugar a la Brillo Box y produjo la mencionada confusión entre arte y realidad. En sus primeros escritos estableció que dicha obra constituyó el fenómeno histórico que lo impulsó a realizar una investigación filosófica en torno a la esencia del arte:

Estos descubrimientos filosóficos emergieron en un determinado momento en la historia del arte y me hicieron ver que la filosofía del arte era rehén de la historia del arte en el sentido en que la verdadera formulación de la pregunta filosófica relativa a la naturaleza del arte no podría haber sido hecha hasta que fuera históricamente posible preguntarla -hasta que fue históricamente posible que hubiera obras de arte como la Brillo Box-. Hasta aquí fue una posibilidad histórica, no una filosófica: después de todo incluso los filósofos están constreñidos por lo que históricamente es posible. ${ }^{58}$

${ }^{56}$ Pop Art. A Critical History, op. cit., p. 279.

${ }^{57}$ Un ejemplo similar al de la Brillo Box lo encontramos en las banderas representadas por Jasper Johns. A través de estas obras Johns realiza una clara crítica al modelo representacional. El problema en este caso consiste en que hasta qué punto la representación de una bandera es ya una bandera. El ejemplo de Jasper no es tan extremo como el de Warhol, sin embargo podemos considerar que es un antecedente claro de la identificación de un objeto con el arte: "When Johs made an American flag the subject of a painting, he invited a substancial list of questions about both the image and the way he painted it. The flag is the kind of image so frequently exposed that we have literally become blind to it. In the context of the painting, we ask ourselves whether the artist is really serious or not (the banality of the new images always raises this question). We might then wonder whether it is even legal to paint a flag. Short of obscenity, it is hard to think of a situation which could be more unsettling to us than the conflicts presented by this image." (Alan Solomon, "The New Art", en Pop Art. A Critical History, op. cit., p. 95.)

${ }^{58}$ Arthur C. Danto, Después del fin del arte..., op. cit., p. 57. 
En la reformulación de su teoría plantea que dicha característica surgió a partir de la obra de Marcel Duchamp y que en esta medida el arte Pop es heredero de sus principios. Sin embargo, como he mostrado, la concepción de esta última corriente sigue apegada a una actitud retinal y por tanto sus obras mantienen una relación muy estrecha con la forma tradicional de comprender el arte. ${ }^{59}$ Se vuelve entonces indispensable mostrar el origen y el sentido de los readymades en su obra.

El artista francés se encargaba de trasladar un objeto o una herramienta cualquiera del mundo al arte, eliminar todo referente común que hayamos tenido sobre esa cosa, dotarla de un contexto diferente y de un nuevo significado. Duchamp negaba la naturaleza del objeto y lo inutilizaba para llamar la atención sobre un aspecto distinto de su finalidad práctica. Esto podemos verlo en la misma denominación de sus obras, pues al adoptar un objeto previamente hecho (alreadymade), el artista ya no tiene que crear nada nuevo, sino que resulta suficiente con apropiarse del objeto y trasladarlo. ${ }^{60}$

Manipulaba los objetos de formas muy diversas, alterando alguna parte, destruyéndolos, cortándolos, pegándolos y mezclándolos. Esta clase de ready-mades han sido llamados 'asistidos'. Otra de las técnicas que utiliza para conformar estas obras consiste en la simple presentación del objeto, realizando un cambio de posición, con lo cual se paraliza su función práctica. A dichos ready-mades los denominó 'puros'. En el fondo, este tipo de trabajos nos muestra que por medio de una intervención un objeto cualquiera tiene la posibilidad de convertirse en otra cosa, inclusive en una obra de arte. ${ }^{61}$

${ }^{59} \mathrm{Al}$ principio, la validez de dicho traslado produjo un claro escándalo e indignación por parte de los artistas convencionales. Nadie se hubiera imaginado que una caja de detergente, una lata de sopa o una hamburguesa reales, iban a encontrarse en una galería de arte. Lo peculiar de estas obras se debe a que son representaciones de diseños comerciales, los cuales comienzan a tratarse como obras de arte. (Cfr. John Rusell, "Pop reappraised", en Pop Art. A Critical History, op. cit., p. 175.)

${ }^{60}$ Cfr. Dalia Judovitz, op. cit., p. 76.

${ }^{61}$ Este tipo de obras marcaron una fuerte influencia de Duchamp en el arte actual pues la intervención forma parte de varios movimientos artísticos posteriores. Entre dichas manifes- 
Al respecto, es necesario recordar que la incorporación de un objeto externo a la obra de arte tuvo su origen en la técnica del collage iniciada por el Cubismo. Lo relevante de este gesto consiste en la crítica de Picasso al carácter representacional de la pintura y la extensión del cuadro como parte de la realidad. ${ }^{62}$ Así, el pintor español muestra un modo de intervención que no es tan radical como el de Duchamp, pero que marca una clara superación de los límites establecidos entre arte y realidad:

El pedazo de cesta que Picasso pega en un cuadro puede ser elegido teniendo una intención de composición; como pedazo de cesta sigue formando parte de la realidad, y se incorpora al cuadro tal cual es, sin experimentar cambios esenciales. De esta manera se violenta un sistema de representación que se basa en la reproducción de la realidad, es decir, en el principio de que el artista tiene como tarea la transposición de la realidad. ${ }^{63}$

En este mismo sentido, Duchamp critica la práctica representacional pues por medio de los ready-mades cuestiona el concepto de reproducción y autenticidad. Como ejemplo tenemos su conocida Fuente, de la cual no se posee el original, sino tan sólo una fotografía. Por otro lado el urinario es un ejemplar de un producto en masa, de

taciones se encuentra el body art, el cual se caracteriza porque el creador utiliza su cuerpo como materia prima y lo altera de diversas formas. Otro tipo de intervención la tenemos en el land art, el cual a partir de un paisaje natural crea un paisaje artificial. En ambos casos no se trata de producir algo nuevo, sino de manipular algo previamente existente y trasformarlo.

${ }^{62}$ De este modo se produce una fuerte escisión en la totalidad que compone el cuadro, por lo que en oposición a dicha integridad se da una discontinuidad. Dicho fenómeno se dio como una fuerte crítica al carácter figurativo de las artes plásticas y sobre todo a la práctica representacional. Esto nos muestra un antecedente de la intención de Marcel Duchamp al presentar sus ready-mades, pues en su caso ya no se tratará de incorporar fragmentos reales, sino la realidad misma: "La obra de arte se transforma esencialmente al admitir en su seno fragmentos de realidad. Ya no se trata sólo de la renuncia del artista a la creación de cuadros completos; también los cuadros mismos alcanzan un status distinto, pues una parte de ellos ya no mantiene con la realidad las relaciones que caracterizan a las obras de arte orgánicas: no remiten como signo a la realidad, sino que son realidad." (Peter Bürger, op. cit., p. 142.)

${ }^{63}$ Peter Bürger, op. cit., p. 140. 
manera que el artista no lo crea directamente. Además la autenticidad de la obra resulta poco clara, pues firma con un pseudónimo: 'R. Mutt'. Con todos estos elementos podemos darnos cuenta que no sólo se cuestiona la atribución de la obra, sino que también se muestra que ésta no es una condición indispensable en el arte:

Cada uno de estos desplazamientos involucra una violación al criterio tradicional para definir qué es una obra de arte: 1) el urinario no es un objeto original, pues es un producto masivo, 2) una reproducción (una fotografía) se exhibe en lugar del original, 3) el uso de un pseudónimo para firmar el trabajo nos hace cuestionar su autenticidad, 4) es difícil atribuir el trabajo a un solo autor, pues su reproducción implica a otros, y, 5) el espectador no ve el original, sino que lo conoce a través de una reproducción. En cada uno de estos puntos vemos cómo uno de los términos que eran necesarios para definir el arte queda desplazado, por lo cual las condiciones clásicas resultan insuficientes para definir el arte. ${ }^{64}$

De este modo, se elimina al artista como parte del proceso creativo, pues su intervención en la obra es posterior. La originalidad de Duchamp radica en hacer girar el arte sobre sus propios medios, en pocas palabras, sobre su condición de posibilidad. ${ }^{65}$ En los ready-mades la producción no tendrá un lugar prioritario y en esa medida parecerá que el artista adquiere un rol pasivo respecto a su obra. Sin embargo, es necesario considerar que la intervención del artista seguirá dándose, pero de forma indirecta. ${ }^{6}$

Esta característica no es exclusiva del Dadaísmo y de la obra del artista francés, pues se relaciona con el propósito general de las vanguardias de anular todo vínculo entre el objeto creado y el individuo. Esto se debe, en último término, a que se ponen en duda la serie de factores

${ }^{64}$ Dalia Judovitz, op. cit., p. 127.

${ }^{65}$ No debemos olvidar que esta actitud frente al arte comenzó con el Modernismo y en concreto con el Impresionismo. Sin embargo, la diferencia entre dicha corriente y la obra de Marcel Duchamp se debe a que en el caso del último ya no es posible hablar de representación, además de que se da un claro alejamiento de las propiedades estéticas en el arte.

${ }^{66}$ Cfr. Dalia Judovitz, op. cit., p. 119. 
por los cuales un determinado objeto había sido aceptado dentro de la esfera artística. Por esta razón, cuando Duchamp firmó el urinario, cuestionó el sentido que tenía la atribución como parte de la práctica artística de su época. Así, no sólo negó el carácter productivo del arte, sino también la diversidad de principios por los cuales se determinaba su carácter restrictivo:

En sus manifestaciones extremas, la vanguardia no propone una creación colectiva, sino que incluso niega radicalmente la categoría de producción individual. Cuando Duchamp firma en 1913 productos en serie (un urinario, una escurridera) y los envía a las exposiciones, está negando la categoría de la producción individual. La firma, que conserva precisamente la individualidad de la obra, es el hecho despreciado por el artista al exhibir productos en serie cualesquiera a modo de burla, frente a toda pretensión de creación individual. La provocación de Duchamp no sólo descubre que el mercado del arte, que atribuye más valor a la firma que a la obra sobre que ésta figura, es una institución cuestionable, sino que hace vacilar el mismo principio del arte en la sociedad burguesa, conforme al cual el individuo es el creador de las obras de arte. ${ }^{67}$

Redefine los objetos en tanto que pone en duda su estatuto ontológico. Cuando escoge un objeto en específico y lo traslada al museo, podemos decir que lo vuelve único, no porque posea ciertas cualidades internas, las cuales lo diferencian de los demás, sino porque el artista es quien le brinda un nuevo significado:

Los ready-mades redefinen la noción de creatividad artística, pues no involucran una producción manual de objetos, sino una reproducción intelectual. La intervención de Duchamp consiste en redefinir el estatus de los objetos y las representaciones; por el carácter objetual de los readymades se afirma su estatuto especial, en cuanto reproducciones que analizan y cuestionan la función representacional del arte. ${ }^{68}$

${ }^{67}$ Peter Bürger, op. cit., p. 107.

${ }^{68}$ Dalia Judovitz, op. cit., p. 76-7. 
Al eliminar la referencia, lo único que nos queda es la presencia, el objeto deja de asociarse con algo externo y está completo por sí mismo. En este caso podemos hablar de una cierta transparencia, la cual más que mostrar la identidad del objeto nos revela la forma en que éste aparece simple y llanamente en nuestra vida diaria. Por tanto, el ready-made generó un nuevo tipo de condiciones en las cuales la experiencia visual y el reconocimiento inmediato de la obra quedaron suplantados por la presentación de un objeto común y corriente. ${ }^{69}$

\section{La creatividad y el proceso de producción}

El Pop Art se desenvolvió en forma muy complaciente y buscó reivindicar las formas de vida de la sociedad norteamericana. No existe una actitud crítica y por tanto su intención no es primordialmente reflexiva, pues simplemente se centró en la apariencia del mundo y la sociedad. Por esta razón, sigue poniendo el énfasis en el tema de la representación y por tanto no pretende ir más allá de la imagen:

La actitud de los artistas pop es diferente. No aspiran a interpretar o representar, sino solamente a presentar. Este tipo de artista cede su autoridad a la casualidad, a pesar de que ellos mismos producen su obra o la exponen a una audiencia, la cual suponen que se encargará de completar el proceso. Los artistas recientes de esta corriente son los primeros de la historia que permiten a todo el mundo participar de su creatividad, sin que por esta razón impliquen una intención de protesta. ${ }^{70}$

De esta manera, nos encontramos con que el Pop Art no trata de centrarse en complejidades, no busca descubrir significados ocultos, ni abordar sus temas de forma rebuscada, sino que parte del mundo exterior y no desea otra cosa más que representarlo tal cual. Sobre esta característica del Pop Art, Lichtenstein opina que:

${ }^{69}$ Cfr. Dalia Judovitz, op. cit., p. 113.

${ }^{70}$ Dore Ashton, “A Symposium on Pop Art”, en Pop Art. A Critical History, op. cit., p. 70. 
¿El arte Pop es despreciable? ¿Eso no suena muy bien, o sí? Pienso que esto implica una relación con las características más desagradables $\mathrm{y}$ violentas de nuestra cultura, cosas que odiamos, pero que poseen algo poderoso en la forma en que nos amenazan. Yo creo que a partir de Cézanne el arte se hizo extremadamente romántico e irreal, y desde mi perspectiva esto es utópico. El arte cada vez tiene menos que ver con el mundo, se ha convertido en algo mentalmente interno, neo-Zen y en otras cosas semejantes. Esto más que una crítica es una observación obvia. Afuera está el mundo, está ahí. El Pop Art mira hacia el mundo, acepta su entorno, el cual no es bueno, ni malo, sino diferente -en el fondo se trata de otro estado de la mente. ${ }^{71}$

En oposición, encontramos que en la obra de Marcel Duchamp existe un profundo valor intelectual. El artista francés no sólo reformuló el significado de los objetos, sino del arte mismo, le dio un giro radical y lo relacionó estrechamente con un planteamiento filosófico. ${ }^{72}$ Con sus trabajos Duchamp se cuestionó sobre los principios del arte, se planteó si éste podía ser encajonado y clasificado invariablemente. De este modo el carácter autoreflexivo del Modernismo se acentuó con el surgimiento de las vanguardias:

Duchamp renuncia nuevamente a este equilibrio, aunque sin regresar a la situación anterior, sino dándole la vuelta por completo: en Duchamp, la concepción se convierte en una variable y pasa a ocupar el primer plano de forma exhibicionista, mientras que su realización o ejecución, en cuanto mero ejercicio de oficio, queda desplazada a un plano secundario. Esta inversión es una característica general del manierismo y se convierte en una tendencia determinante de la modernidad postclásica. La exhibición usurpa el lugar de las estructuras idealizadas (los cánones

${ }^{71}$ G. R. Swenson, "What is Pop art?”, en Pop Art. A Critical History, op. cit., p. 107.

${ }^{72}$ Para el arte contemporáneo las ideas tendrán un lugar central y en muchos casos serán lo único que dote de sentido a la obra. Los trabajos de Marcel Duchamp se nos presentan como un claro antecedente del arte conceptual, surgido en 1960. En el caso del artista francés el objeto sigue teniendo un papel central, sin embargo en el arte conceptual el objeto quedará completamente desplazado por la idea. La obra de Daniel Buren es un caso ejemplar de dicho tránsito. (Cfr. David Hopkins, op. cit., p. 161-2). 
artísticos). Se expresa bajo una forma que, por su propia esencia, les había estado reservada a éstas: bajo la forma del concepto [...] es en el concepto mismo donde la exhibición individual encuentra su forma artística, en él se condensa el 'sí mismo grandioso'. El concepto se convierte en la maniera de la modernidad. ${ }^{73}$

Por esta razón sus diversos trabajos, más que situarse en la experiencia de los sentidos, se sitúan en una experiencia intelectual. De aquí se desprende su marcada influencia por parte del arte abstracto y en particular del Cubismo. Es necesario aclarar que dicho peso intelectual en el arte no es exclusivo de Marcel Duchamp, pero sí la forma en que lo incorpora a sus obras y lo sitúa como un punto de referencia para el futuro desarrollo del arte, como fue el caso del arte conceptual. ${ }^{74}$

El artista francés no sólo se cuestiona qué es el arte, sino también el modo en que lo interpretamos. Por esto su propuesta se relaciona estrechamente con una consideración lingüística y se desplaza constantemente entre la realidad y las palabras. Duchamp se pregunta sobre el modo en que las convenciones alteran las diversas visiones del arte que se han generado a lo largo de la historia, además de plantearse si es posible establecer un criterio objetivo para juzgarlo.

Surge la pregunta sobre si este tipo de trabajos pueden clasificarse propiamente como obras artísticas o más bien se trata de una crítica al arte, a la elaboración de un complicado entramado intelectual para demostrar la invalidez de los principios artísticos anteriores. En este sentido me parece que el ready-made se asocia más con el proceso creativo que con la realización práctica:

${ }^{73}$ Sandro Bocola, op. cit., p. 297-8.

${ }^{74}$ Sobre esto encontramos una serie de ejemplos históricos que nos dejan ver que otros creadores ya habían tomado el aspecto intelectual como parte clave de sus obras. Un artista que presentaba esta concepción del arte fue Leonardo da Vinci, para quien el arte era primordialmente el registro de un proceso intelectual, más que de una experiencia visual. Por esta razón da Vinci se centró más en la formulación de sus ideas que en la producción de obras de arte. Esta característica es compartida por Duchamp, para quien también fue más importante el rol intelectual. (Cfr. Dalia Judovitz, op. cit., p. 79.) 
¿Qué tipo de objeto es el ready-made? Su carácter tridimensional sugiere su afinidad con la escultura, mientras que su referencia al lugar común sugiere un juego de palabras sobre la realidad objetiva de la obra de arte. ¿El ready-made es una obra de arte o es un fenómeno crítico? Y si el ready-made no es una obra de arte, ¿cómo mantiene su distancia crítica, sin formar parte de su esfera? En este contexto, ¿qué corresponde al artista y al acto creativo? ${ }^{75}$

A pesar de lo determinante que resulta el entramado teórico en la obra de Duchamp, no podemos considerar que lo único relevante sea dicho aspecto, pues el concepto no puede separarse de la obra; la manipulación de los objetos, el empleo de una diversidad de materiales y el juego con lo establecido, abrirán la esfera artística a otras dimensiones. ${ }^{76}$

Sobre este aspecto encontramos que la mayoría de sus trabajos están complementados por una serie de notas y documentos, los cuales nos permiten comprenderlo mejor. Lo curioso consiste en que estos papeles han sido tomados por sí mismos como arte. En mi opinión, dichos textos más que tratarse de una serie de claves para explicar sus trabajos nos muestran el peso teórico de su obra. ${ }^{77}$

Por otro lado, no puede considerarse que dicha implicación intelectual tenga una pretensión académica, sino que posee una naturaleza doble, en la que se mezcla la crítica con el humor. En este sentido, su obra posee una fuerte carga lúdica y un ingenio mordaz, por lo cual recurre constantemente a la paradoja y la ironía. Como he insistido,

${ }^{75}$ Dalia Judovitz, op. cit., p. 96-7.

${ }^{76}$ Sobre ello David Hopkins apunta que después de Duchamp el arte dejó de centrarse en el objeto para hacerlo en el concepto. Con los ready-mades eliminó la vestidura material de la obra y la cubrió con una consideración analítica. De este modo descubrimos la influencia de Duchamp en movimientos posteriores como fue el caso de Fluxus. (Cfr. David Hopkins, op. cit., p. 177.)

${ }^{77}$ El peso intelectual de las obras de Marcel Duchamp es un rasgo que las separa del planteamiento y de las creaciones del Pop Art. En este sentido encontramos en sus obras un rasgo común en las diversas vanguardias y esto es la importancia del documento como fundamento de la obra. Al respecto tenemos el gran número de manifiestos que surgió en dicha época, los cuales sirvieron de base crítica e ideológica a los diversos movimientos. 
ésta es una de las características que lo pondrán por encima de los dadaístas, pues su manera de juzgar y reformular el arte no es recurriendo al absurdo, sino por medio de la burla intelectual. ${ }^{78}$

\section{El fin de la belleza}

Danto plantea que con la aparición del Expresionismo abstracto en la década de los sesenta se dio un tipo de arte alejado de la belleza y sobre todo de un trato metafísico sobre el mismo. Le parece que el Expresionismo abstracto se acercó a la intención explícita de la filosofía analítica de separarse de una concepción ontológica sobre las diversas manifestaciones humanas, incluido el arte. Esta ruptura con la historia y la filosofía del arte se acentuó con el surgimiento del Pop Art, el cual terminó por separar la belleza de las obras al confundirlas con la realidad. En esta medida el filósofo norteamericano está convencido de que dicho movimiento presenta una serie de elementos correspondientes a su propia concepción sobre el desenvolvimiento e interpretación del arte:

Me desconcertó la pregunta sobre cómo era posible que las cajas de Warhol fueran consideradas obras de arte, mientras que sus homólogos en la vida cotidiana fueran tratados como paquetes útiles, sin ninguna pretensión artística. La estética no puede aplicarse a este caso, pues los dos tipos de cajas, mostraban identidades filosóficas tan parecidas entre una y otra, que resultaba prácticamente imposible que una de ellas presentara cualidades estéticas que la otra no poseía. Por esta razón la estética salió de la ecuación y no apareció en la literatura posterior que originó mi ensayo titulado El mundo del arte de $1964 .^{79}$

${ }^{78}$ Él mismo considera que los ready-mades manifiestan un tipo de metaironía, mediante la cual se propone mostrar una anestesia visual y una indiferencia estética. Se trata de una metaironía pues Duchamp se cuestiona con ella sobre qué es el arte y por esta razón podemos decir que se pone por encima de él. (Cfr. Dalia Judovitz, op. cit., p. 117.)

${ }^{79}$ Arthur C. Danto, The Abuse of Beauty, op. cit., p. 3. 
Asimismo muestra que lo paradójico de su obsesivo interés en la Brillo Box de Andy Warhol se debió en gran parte a que se sintió atraído por las cualidades estéticas intrínsecas a esta obra. Por dicha razón plantea que sus características pertenecen al diseño de la caja de detergente, que tuvo como finalidad volverlo un producto atractivo para el consumidor. De manera que el responsable de dicho efecto fue su autor original, James Harvey y no Andy Warhol:

Mi especial atención filosófica en la Brillo Box se debió a una decisión como cualquier otra de nuestra vida, basada en diferencias estéticas. Este es un buen ejemplo de la forma en que el diseño determina el gusto -nos hace escoger un producto en lugar del de la competencia, por lo cual escogemos un detergente o una corbata o para el caso una pintura en óleo. Gran parte del éxito del Pop Art como movimiento mundial se debe a que sus representantes se apropiaron de los logros de diseñadores desconocidos, hechos con el propósito inicial de tomar productos prestados en el límite de una simple ventaja comercial. ${ }^{80}$

Según él ocurrió algo muy similar en el caso del Dadaísmo y la obra de Marcel Duchamp, pues considera que en el fondo ambos movimientos se caracterizaron por su rechazo a la belleza, a pesar de que sus obras poseían cualidades estéticas. En esta medida Danto plantea que el problema de la definición del arte surge con los trabajos del artista francés y se acentúa con la aparición del Pop Art. Desde su perspectiva, las propiedades estéticas que conforman las manifestaciones de ambos movimientos son incidentales, lo que significa que dichas cualidades no se buscan en sí mismas, sino que están adheridas a las obras y por esto no constituyen un principio esencial de ellas. Tanto en el diseño original de la caja de detergente en el que se basa Warhol, como en el urinario que utiliza Duchamp existe una dimensión estética, que queda anulada en la intervención posterior:

Mientras tanto es de cierto valor reconocer que la conexión entre Fuente y el urinario del cual Duchamp se apropio está muy relaciona${ }^{80}$ Idem, p. 6. 
da con la Brillo Box de Warhol y la caja de Brillo diseñada por James Harvey. Fueron las cualidades estéticas de la última las que me hicieron interesarme en la primera, que no presenta ninguna cualidad estética más que la correspondiente a las cajas de Harvey. Sin embargo, ninguna de las cajas de Harvey tuvo la profundidad filosófica de las de Warhol, por la misma razón que el urinario manufacturado por Mott Iron Works no tuvo el poder filosófico y artístico de la Fuente, la cual ayudó a transformar la historia del arte. Pero resulta cuestionable pensar que el poder estético de los urinarios, diseñados para ser atractivos del mismo modo que las cajas de Brillo, corresponde a la Fuente como una obra de arte. En este caso, la disonancia de Fuente no es una propiedad de los urinarios, perfectamente diseñados para los baños. En todo caso, subyace una pregunta metafísica similar entre distinguir la Fuente del urinario del cual fue tomada y diferenciar entre una persona y su cuerpo. ${ }^{81}$

Danto considera que la intención antiestética es compartida por el Pop Art y está convencido de que ambos movimientos responden a un proyecto similar. ${ }^{82}$ Sin embargo, como he ido demostrando, ambas corrientes presentan motivaciones e intereses muy diferentes. En primer lugar, esto se ve por el modo en que hacen uso de la vida cotidiana. En esta medida el Pop Art retoma una serie de aspectos pertenecientes a la experiencia diaria, pues pretende hacer al arte más accesible y menos complejo. En cambio el Dadaísmo, a partir de los mismos elementos, busca anular el carácter convencional del arte y destruir cualquier noción estable sobre el mismo.

El Pop Art se mantiene muy relacionado con el placer que produce la imagen visual, de aquí que tenga como finalidad principal retomar la estructura de la publicidad, los medios masivos de comunicación y las formas de vida de la clase media norteamericana. Por esta razón

${ }^{81}$ Idem, p. 11-2.

${ }^{82}$ Para el filósofo norteamericano la conexión entre la Brillo Box de Andy Warhol y la Fuente de Marcel Duchamp resulta evidente, pues plantea que ambas obras de arte se caracterizan por extraer un objeto de la vida cotidiana y elevarlo a la categoría de obra artística. Danto considera que ambas muestran el poder del autor sobre la obra y que por tanto la producción de arte se desenvuelve como una especie de bautizo, en el cual se dota de un nuevo significado al objeto. 
se ocupa de la apariencia como su tema central, pues como el mismo Danto señala, incorpora una serie de elementos que hacen atractivos a los productos comerciales y por tanto sus obras siguen presentando cualidades estéticas.

Dicha corriente tiene una pretensión que podríamos considerar como exhibicionista, pues busca ser admirada e inclusive idolatrada. Es un arte complaciente, el cual exige poco al público y se regodea en la inmediatez y la banalidad. En este sentido me parece que el arte Pop no presenta una dimensión crítica, ni tampoco una carga reflexiva en sus trabajos, por lo que más que marcar un abandono de la belleza constituye una reivindicación de dichas cualidades en los objetos más inverosímiles. Los artistas de este movimiento más que negar la belleza como parte de sus obras tienen la intención de ampliar la proyección de la misma fuera del arte. Su lucha no es en contra de la estética, sino del carácter restrictivo del arte, pues buscan ampliar sus límites y establecer que la belleza puede encontrarse en los lugares más comunes.

Además, la Brillo Box es una obra creada por Andy Warhol, de modo que todavía se trata de un objeto elaborado y no sólo implica una forma de apropiación. Por esta razón, dicha obra no puede clasificarse como un ready-made pues en el fondo sigue siendo la representación de una caja de detergente. Por tanto, pienso que la implicación filosófica que Danto le adjudica a los trabajos de Andy Warhol corresponde propiamente a la obra de Marcel Duchamp.

Éste se sitúa muy por encima de la narrativa representacional y en este sentido su concepción artística supera los límites establecidos en su época ${ }^{83}$ Realiza una crítica al carácter unitario del arte y sobre todo

${ }^{83}$ Por otro lado, podemos darnos cuenta de que esta característica no es exclusiva de la obra de Duchamp y que es compartida por otros artistas, al menos en cierto modo. Al respecto tenemos el caso de Jasper Johns quien logra una confusión entre lo presentado y lo representado. La forma en que consigue este efecto es representando algo, cuya presencia se identifique con su representación, como ocurre con las banderas o los números. De este modo Jasper se sitúa a un paso de los ready-mades, pues todavía hace uso de la pintura, para criticar la narrativa representacional. (Cfr. David Hopkins, op. cit., p. 58-61). 
a la idea de que la obra depende exclusivamente de su autor. Con la aparición de los ready-mades renunció a una estética visual, razón por la cual en este tipo de trabajos ya no puede hablarse de una cuestión de gusto. Duchamp estableció una categoría nueva al presentar algo que no produce ninguna emoción estética:

En general yo debo tener cuidado con esta 'mirada'. Es muy difícil escoger un objeto, porque al final de quince días comienzas a apreciarlo o detestarlo. Tienes que acercarte a algo que resulte indiferente, como si no sintieras emoción estética alguna. La selección del ready-made está basada siempre en la indiferencia visual y al mismo tiempo en una total ausencia de buen o de mal gusto. ${ }^{84}$

Esto se debe en gran parte a que los ready-mades se caracterizaron por la neutralidad con que sus objetos eran presentados, por lo que dichas obras mostraban un carácter radicalmente tautológico. Al respecto tenemos su conocida Fuente, la cual consistió en la apropiación de un urinario, la firma del mismo y su traslado a la esfera artística. ${ }^{85}$ Por medio de esta obra se puso en duda la relación entre arte y belleza, pues al igualar el arte con una pieza de fontanería, las cualidades estéticas dejaron de fungir como el criterio adecuado para distinguir el arte de lo que no es:

Los ready-mades fueron apreciados por Duchamp precisamente por ser imposibles de describirse en términos estéticos, y demostró que sí eran arte pero no bellos, la belleza realmente no podría formar parte de ningún atributo definitorio del arte. Podría decirse que este reconocimiento dibuja una línea muy nítida entre la estética tradicional y la filosofía del arte, que incluye la práctica actual del arte. ${ }^{86}$

${ }^{84}$ Dalia Judovitz, op. cit., p. 97.

${ }^{85}$ Lo que resulta curioso es que algunos artistas y críticos creyeron que Duchamp estaba tratando de llamar la atención sobre la 'blanca pureza' del urinario y por tanto se refería a su belleza. Sin embargo esto implicó un alejamiento de su intención, pues por medio de este gesto el artista francés realizó una crítica a dicho paradigma y cuestionó su sentido en la conformación de una obra de arte.

${ }^{86}$ Arthur C. Danto, Después del fin del arte..., op. cit., p. 100. 
La manera en que se logró este efecto fue mediante la alteración del contexto y la indiferencia perceptual. Lo característico de la última consiste en que deriva en una eliminación del criterio estético y por tanto el gusto termina por anularse. Sobre este punto el artista francés nos muestra la intención de sus ready-mades, especialmente su distancia frente a la práctica representacional y su deseo de superar la actitud retinal en el arte:

Los creé sin intención alguna, sin más premeditación que la de desprender ideas. Cada ready-made es distinto. Entre los diez o doce ready-mades no hay ningún denominador común, salvo el que todos ellos son mercancías manufacturadas. Por lo que respecta al rastreo de una idea en cuanto hilo conductor: no. Indiferencia. Indiferencia frente al gusto: ni gusto en el sentido de la reproducción fotográfica ni gusto en el sentido de un material bien hecho. El punto común es la indiferencia. Podría haber escogido veinte objetos distintos por hora, pero al final todos habrían mostrado el mismo aspecto. Eso es algo que quería evitar a toda costa. ${ }^{87}$

Por medio de la indiferencia perceptual y la anulación del juicio estético para tratar sus trabajos, Marcel Duchamp volvió muy compleja la posibilidad de definir qué era el arte o al menos de establecer por qué sus obras eran tratadas en esa forma. Como consecuencia de dicho gesto eliminó todo criterio estable e impidió realizar una lectura unívoca de lo que presentaba:

La realidad última no es una fuerza ni una ley que pudieran ser descubiertas más allá o debajo de las apariencias, sino que tienen sede en el hombre mismo. La realidad última es la arbitrariedad humana. Sólo ella proporciona su sentido a las apariencias y en esto consiste el acto creativo. De manera soberana, Duchamp escapa a todo compromiso y establece su propia escala: bajo la forma de su elección. Mediante este provocador desprecio hacia toda convención se manifiesta en su gesto

\footnotetext{
${ }^{87}$ Sandro Bocola, op. cit., p. 305.
} 
una fantasía arcaica y grandiosa que se convierte en una de las visiones dominantes de la evolución artística del porvenir: la fantasía irracional de una libertad sin condiciones. ${ }^{88}$

En los ready-mades de Marcel Duchamp encontramos los siguientes principios, que no son equiparables con las obras del movimiento norteamericano: la expresión subjetiva es desplazada por la presentación de algo que en sentido estricto es anónimo, que carece de autoría; el azar constituye una parte fundamental del proceso artístico y se anula cualquier tipo de necesidad; la arbitrariedad personal sustituye al canon estético; el arte deja de pertenecer a un ámbito restringido, incluyendo el del museo; la elección de un objeto sustituye la producción de una obra; el proceso creativo se centra más en la concepción que en la construcción de algo; el mensaje de la obra resulta desconcertante y adquiere la forma de un enigma. ${ }^{89}$

Es necesario considerar que la carga transgresora de los trabajos de Duchamp, y de las vanguardias en general, correspondió a un momento histórico en el cual se cuestionó radicalmente la noción tradicional del arte y la serie de principios que configuraban la gran mayoría de las obras en esa época. ${ }^{90}$ La intención crítica y de protesta originada en la obra del artista francés no puede equipararse con un gesto similar en el caso de un artista actual. Esto se debe a que la institución a la que Duchamp se oponía terminó por aceptar sus trabajos y ahora forman

${ }^{88}$ Idem, p. 307.

${ }^{89}$ Idem, p. 295.

${ }^{90} \mathrm{Sin}$ embargo, es necesario considerar que a pesar de que el Dadaísmo se caracterizó por rechazar el estatuto de obra de arte, sus manifestaciones se volvieron obras artísticas. Esto significa que a pesar de su lucha en contra de la obra y la institución del arte, terminaron por asimilarse dentro de dicha dinámica. Por esta razón me parece que uno de los principales efectos que producen las vanguardias consiste en la ampliación de los límites de la esfera artística: "El objet trouvé, la cosa, que no es el resultado de un proceso de producción individual, sino el hallazgo fortuito en el cual se materializa la intención de vanguardista de unión del arte y la praxis vital, hoy es reconocido como obra de arte. El objet trouvé ha perdido su carácter antiartístico, se ha convertido en una obra autónoma que tiene un sitio como las demás en los museos." (Cfr. Peter Bürger, op. cit., p. 114.) 
parte de los museos, además de constituir un referente obligado en la historia del arte:

Cuando la obra consigue organizarse en torno al compromiso, su tendencia política corre un nuevo peligro: la neutralización por la institución del arte. La obra ingresa en un contexto de creaciones cuyo punto en común consiste en la reunificación con la praxis vital, y se percibe tendencialmente al establecer su compromiso desde el principio estético de la organicidad como un mero producto artístico. La institución arte neutraliza el contenido político de las obras particulares. ${ }^{91}$

El propósito de Duchamp y las vanguardias se vio superado por el hecho de que su serie de factores emancipadores terminaron por formar parte de la esfera artística y de sus convenciones. Este fenómeno marcó una clara diferencia con el arte postvanguardista, pues en su caso ya no es posible hablar de una crítica radical ni de un compromiso social. Así, aunque tomáramos la obra de Andy Warhol por un cierto tipo de ready-made, no lo sería en sentido estricto pues su autor deseaba que perteneciera al mundo del arte. El carácter provocativo que Danto encuentra en el Pop implica, por el contrario, una intención

64 conciliadora y un fuerte deseo de inclusión:

La provocación depende de cuál sea su objetivo: en este caso se trata de la idea de que el arte lo crean los individuos. Pero, una vez que el urinario firmado se acepta en los museos, la provocación no tiene sentido, se convierte en lo contrario. Cuando un artista de hoy firma y exhibe un tubo de estufa, ya no está denunciando el mercado del arte, sino sometiéndose a él; no destruye el concepto de la creación individual, sino que lo confirma [...] Cuando la protesta de la vanguardia histórica contra la institución arte ha llegado a considerarse como arte, la actitud de protesta de la neovanguardia ha de ser inauténtica. De ahí la impresión de la industria del arte que las obras neovanguardistas provocan con frecuencia. ${ }^{92}$

${ }^{91}$ Peter Bürger, op. cit., p. 161.

${ }^{92}$ Idem, p. 107. 
Desde mi perspectiva, uno de los aspectos que resulta más llamativo e interesante de los ready-mades consiste en que el sujeto ya no interviene directamente en la obra y el sustento material de la misma se va desvaneciendo cada vez más hasta que su carácter teórico e intelectual termina por situarse en primer plano. Pienso que la influencia y proyección de la obra de Marcel Duchamp en el arte contemporáneo resulta innegable. Inclusive sería motivo de otro análisis plantear el modo en que el arte-objeto se relaciona con movimientos como el land art, el body art y el arte conceptual.

Por último, a manera de conclusión, debo decir que los readymades revolucionaron la forma de entender el arte, dando lugar a una interpretación completamente distinta y abriendo sus posibilidades hacia otros horizontes. Dichos trabajos marcaron un alejamiento del naturalismo pictórico que tuvo como consecuencia una nueva concepción sobre la pintura y el arte en general. Por tanto, la búsqueda por copiar la realidad con excesiva fidelidad fue desplazada por un fenómeno más radical. En el arte actual ya no se trata de representar la realidad, sino de extraerla y adoptarla tal cual. 
CITAM Derechos Reservados.

La reproducción total o parcial de este artículo se podrá hacer si el ITAM otorga la autorización previamente por escrito. 